\title{
LA METTRIE E O CARTESIANISMO
}

\author{
Mauro Dela Bandera Arco Júnior ${ }^{1}$ \\ Universidade de São Paulo (USP) \\ (iD) https://orcid.org/0000-0002-9672-2483 \\ E-mail: maurodelabandera@yahoo.com.br
}

\section{RESUMO:}

O homem-máquina de La Mettrie aparece constantemente ligado ao animal-máquina cartesiano. A partir desta relação, é possível indagar se existe verdadeiramente alguma continuidade entre a proposta cartesiana e a defendida por La Mettrie ou, ao contrário, se esta última representa de modo efetivo uma crítica e uma ruptura em relação à primeira. Nossa interpretação defende que o germe do materialismo - e La Mettrie não escapa disso - só pode desenvolver-se na condição de romper totalmente com a doutrina cartesiana. Assim, longe de haver apenas um passo entre uma e outra teoria filosófica, o que existe é uma diferença radical e gigante. Não há uma continuidade teórica entre o animal-máquina cartesiano e o homem-máquina lamettriano. Diferentemente do que se passa na teoria de Descartes, particularmente, em sua concepção dualista que implica em uma descontinuidade, o Homem-máquina estabelece uma tese continuísta entre homens e animais. Para La Mettrie, a passagem da animalidade à humanidade não é uma passagem violenta, mas sim gradual.

PALAVRAS-CHAVE: La Mettrie; Descartes; Homem-máquina; Animal-máquina.

\section{LA METTRIE AND THE CARTESIANISM}

\begin{abstract}
:
The machine-man of La Mettrie appears constantly connected to the cartesian animal-machine. From this relation, it is possible to inquire whether there is indeed some continuity between the Cartesian proposal and that advocated by La Mettrie or, on the contrary, whether the latter effectively represents a criticism and a rupture with respect to the former. Our interpretation is that the germ of materialism - and La Mettrie does not escape it - can only develop in the condition of breaking completely with the cartesian doctrine. So, far from there being only one step between one and another philosophical theory, what exists is a radical and giant difference. There is no theoretical continuity between the cartesian animal-machine and the lamettrian machine-man. Unlike what happens in Descartes theory, particularly, in his dualistic conception that implies a discontinuity, Machine-man establishes a continuist thesis between men and animals. For La Mettrie, the passage from animality to humanity is not a violent passage, but a gradual one.
\end{abstract}

KEYWORDS: La Mettrie; Descartes; Machine-man; Animal-machine.

${ }^{1}$ Doutorando em Filosofia na Universidade de São Paulo (USP), São Paulo - SP, Brasil.

JÚNIOR, Mauro Dela Bandera Arco. La Mettrie e o cartesianismo. Griot : Revista de Filosofia, Amargosa - BA, v.18, n.2, p.348-361, dezembro, 2018. 
Entre a hegemonia da insensível tese do animal-máquina na metade do século XVII e a proclamação da lei Grammont da França em 1850 - que criminaliza os maus-tratos a animais domésticos em via pública -, houve uma fervorosa disputa no século XVIII sobre o estatuto dos animais.

$\mathrm{Na}$ primeira metade do século XVIII, muitos autores consideravam extravagante a doutrina dos animais-máquinas dos cartesianos. Em 1728, David Boullier (1699-1759) redigiu seu Ensaio filosófico sobre a alma dos animais (bêtes) celebrado por Ehrard como "o livro marcante de meados do século sobre a alma dos animais" (EHRARD, 1994, p. 682) ${ }^{2}$-, reconhecendo a existência da alma espiritual destes, embora inferior àquela encontrada no ser humano (BOULLIER, 1985, pp. 341-353). Uma década mais tarde (1739), o padre Guillaume Bougeant (1690-1743) publicou um livreto intitulado Divertimento filosófico sobre a linguagem dos animais (bêtes), em que também defende a existência da alma nos animais (BOUGEANT, 1954, pp. 49-71). As ideias destes dois autores tornaram-se referências importantes no debate intelectual do período. Em 1751, por exemplo, foram mobilizadas por Claude Yvon (1714-1789) no verbete "Alma dos animais (bêtes)" da Enciclopédia, visando justamente refutar a doutrina cartesiana dos animais-máquinas (Encyclopédie ou dictionnaire raisonné des sciences, des arts et des métiers).

Já em meados do século XVIII, Condillac declarava na abertura do primeiro capítulo do Tratado dos animais (1755) que "o sentimento de Descartes sobre a alma dos animais" começava "a ser tão velho" que, presumivelmente, não lhe restava mais partidários (CONDILLAC, 2004). Charles-Georges Le Roy, caracterizado por Élisabeth de Fontenay como o "caçador das luzes" (FONTENAY, 1998, pp. 465478), acusava muitos autores de terem deteriorado a inteligência dos animais. Para ele, é impossível concordar com a ideia de automatismo dos animais (LE ROY, 2017, p. 172).

Em geral, uma recusa do cartesianismo ou até mesmo um anticartesianismo imperava entre os autores do $\mathrm{XVIII}^{3}$. Via de regra, o objetivo era mobilizar o caso dos animais para melhor esclarecer o lugar e a natureza do homem ${ }^{4}$. Alguns buscavam animalizar os homens, ao passo que outros espiritualizavam os animais (EHRARD, 1994, p. 685), concedendo-lhes muitos atributos (linguagem, faculdade de se aperfeiçoar, entendimento, alma), quando não, quase tudo. Se, por um lado, certos autores defendiam uma não continuidade entre as esferas animal e humana -

\footnotetext{
${ }^{2}$ Em 1737, aparece a segunda edição do Ensaio contendo importantes acréscimos.

${ }^{3}$ De fato, muitos autores do século das luzes eram movidos pela tentativa de recusar as teses cartesianas sobre os animais, o que não significa dizer que não se possa apontar algum partidário e apoiador da doutrina cartesiana ou alguém que retomou alguns de seus pontos. Para um debate mais completo sobre o tema da animalidade e humanidade ao longo do século XVIII, ver o importante trabalho de Hester Hastings (HASTINGS, 1936).

4 De acordo Buffon, no início de seu Discurso sobre a natureza dos animais (1753), "como é somente comparando que podemos julgar que nossos conhecimentos se baseiam inteiramente nas relações que as coisas têm com as que se assemelham a elas ou que diferem delas, e que se não houvessem animais, natureza do homem seria ainda mais incompreensível" (BUFFON, 2010, pp. 111-112). Para Condillac, logo na frase inicial de seu Tratado dos animais, "seria pouco curioso saber o que são os animais se isso não fosse um meio de conhecer melhor o que nós mesmos somos" (CONDILLAC, 2004, p. 111). Os fenômenos "extra-humanos" observados por La Mettrie, como as plantas e os animais, são manejados como espelhos por meio dos quais o homem se olha para melhor se conhecer (VARTANIAN, 1987, pp. 53-54) e para melhor "conhecer a natureza humana" (LA METTRIE, 1981, p. 157).
}

JÚNIOR, Mauro Dela Bandera Arco. La Mettrie e o cartesianismo. Griot : Revista de Filosofia, Amargosa - BA, v.18, n.2, p.348-361, dezembro, 2018. 
não sendo, no entanto, confundidos com os cartesianos -; por outro, alguns sustentaram a hipótese contrária, a da continuidade, isto é, uma não ruptura e uma não diferença de natureza entre o universo humano e o animal.

A ideia de uma continuidade na escala dos viventes em que se passaria por graus insensíveis de uma espécie à outra - incluindo o próprio homem nesse encadeamento - exerceu um papel importante no pensamento do século XVIII. Como ela, torna-se especialmente difícil fixar os limites que separam a animalidade da humanidade (SOUZA, 2002, p. 54). O monismo materialista de Diderot, por exemplo, procura explicar a possibilidade do aparecimento da vida e do pensamento. Segundo ele, a produção de todas as formas de seres, desde os minerais até o homem e sua mente, pode ser explicada pela atividade da matéria, de sorte que não se fala mais de uma diferença ontológica entre as coisas da natureza. Todos os seres devem ser concebidos como modificações, diferenciadas gradualmente, de uma única substância (idem, p. 57). Portanto, entre o animal e o homem a diferença se encontra "apenas na organização" (DIDEROT, 2010, p. 353). Na tríade Diálogo entre d'Alembert e Diderot, Sonho de d'Alembert e Continuação do diálogo, Diderot assevera que "com certa matéria inerte, disposta de uma certa maneira, impregnada de uma outra matéria inerte, do calor e do movimento, obtêm-se sensibilidade, vida, memória, consciência, paixões, pensamentos". Por isso, ele defende a passagem gradual "do mármore ao humo, do humo ao reino vegetal e do reino vegetal ao reino animais, à carne" (idem, p. 346); a passagem de um pedaço de mármore a um ser que sente, e deste a um ser que pensa, isto é, a passagem do ser sensível ao ser pensante.

Nesse mesma linha, o autor do Homem-máquina havia sustentado que a transição da animalidade à humanidade não é violenta (LA METTRIE, 1981, p. 163), sendo por isso partidário da concepção nomeada por alguns de continuísmo psicológico $^{5}$. Não obstante, La Mettrie confessa-se cartesiano, ou melhor, afirma que Descartes estaria na origem de suas posições, sendo o Homem-máquina apenas uma continuação das teses cartesianas. $O$ próprio La Mettrie não cessa de reclamar a paternidade de Descartes - que sabemos, estava muito longe de admitir uma continuidade entre homens e animais. O que pode significar essa declaração de filiação do médico filósofo e quais os limites de seu "cartesianismo" confesso? Eis esboçados os objetivos deste artigo. De um lado, procuraremos reconstituir em linhas gerais a concepção cartesiana de animalidade e, de outro, analisar o projeto lamettriano. Tratar-se-ia de uma continuidade e universalização da proposta cartesiana ou, ao contrário, de sua crítica e de uma ruptura? Nossa interpretação defende que o germe do materialismo, e La Mettrie não escaparia disso, só pode se desenvolver na condição de romper totalmente com a doutrina cartesiana. É preciso realizar uma ruptura nítida, deliberada e metódica com a doutrina cartesiana. Assim, se é verdade que La Mettrie homenageia Descartes de muitas maneiras, ele não retoma em sua obra quase nada da doutrina cartesiana propriamente dita.

\footnotetext{
5 “O continuísmo psicológico [...] é a hipótese ou a concepção metafísica segundo a qual a psicologia humana não é fundamentalmente diferente da psicologia não humana, mas está em uma relação de continuidade com ela. Para La Mettrie, isso significa que a alma ou o espírito dos seres humanos é constituído do mesmo tecido - a "matéria sensível' - que a alma ou o espírito dos animais não humanos. [...] Assim, quaisquer que sejam as diferenças observáveis na psicologia humana e não humana, pode-se ex hypothesi explicá-las pelas diferenças fisiológicas das diferentes espécies e, mais particularmente, por diferenças de grau de organização material, ou de 'perfeição' fisiológica" (MACGUIRE, 2014, p. 117).
}

JÚNIOR, Mauro Dela Bandera Arco. La Mettrie e o cartesianismo. Griot : Revista de Filosofia, Amargosa - BA, v.18, n.2, p.348-361, dezembro, 2018. 
Ainda hoje se discute se Descartes é verdadeiramente o autor da teoria dos animais-máquinas. Alguns intérpretes julgam injusta e caluniosa a opinião comum que atribui a Descartes essa autoria. Eles dizem que os verdadeiros defensores da tese do animal-máquina são os cartesianos, e não Descartes. Para tanto, apoiam-se no fato de Descartes afirmar em uma das respostas às seis objeções às Meditações metafísicas que, se ele recusa a existência do pensamento nos animais, jamais lhes negou "o que comumente se chama vida, alma corporal e sentido orgânico" (DESCARTES, 1996, p. 228). Estes intérpretes ainda acrescentam que a hipótese dos animais-máquinas assume apenas um plano probabilístico nos escritos do autor, já que, contrariamente ao que se passa com os experimentos utilizados para distinguir os animais/autômatos dos seres humanos, é impossível distinguir um animal de uma máquina que simule o comportamento animal.

Não entraremos na polêmica e não nos compete aqui examinar a paternidade desta teoria. Sem a intenção de realizar um processo - o caso Descartes -, objetivamos em um primeiro momento tão somente repassar o quadro conceitual no qual esta concepção pôde ser formulada. Este quadro, que ninguém nega a existência, situa-se em alguns textos: algumas referências discretas presentes no Discurso do método e breves menções em sua correspondência.

Para o autor, o cogito só pode ser experimentado em si mesmo, não sendo alcançável no lugar de outro. Como então saber se um outro homem, um animal ou um autômato são seres pensantes ou meros modos da extensão? Como conhecer o princípio que rege a ação desse homem, desse animal ou desse autômato? E, em que o comportamento do homem difere do comportamento animal? Descartes pretende encontrar um equivalente ao teste de Turing para se decidir sobre a animalidade ou a humanidade. Ele nos fala de um preciso protocolo experimental a ser seguido: estudar de maneira quase behaviorista o animal. Nas palavras de Thierry Gontier, "não podendo experimentar neles o princípio interior de suas ações, tal como faço em mim mesmo, sou reduzido a uma semiologia complexa do comportamento" (GONTIER, 2010, p. 33) ${ }^{6}$. A fim de determinar se os animais possuem ou não uma forma de pensamento que presida suas ações, duas experiências decisivas se deixam ver no Discurso do método: i) as ações industriosas - orientadas pela razão - e ii) a linguagem ${ }^{7}$.

Todos os aspectos do comportamento animal - mesmo as paixões e os sons inarticulados utilizados para expressá-las - podem ser explicados por meio de um mecanicismo, com base na suposição de que o animal é organizado de modo similar a um autômato, bem como na incapacidade de distinguir comportamentos animais do comportamento simulado por uma máquina. $\mathrm{O}$ comportamento do homem, por seu turno, escapa a qualquer tipo de explicação única e exclusivamente mecanicista por se tratar de um ser dotado de faculdades específicas e perpassado por duas substâncias: a coisa extensa e a coisa pensante. Citemos Descartes:

\footnotetext{
${ }^{6}$ Ver também outro artigo do mesmo autor (GONTIER, 1991, pp. 8-9).

7 De acordo com Gontier, nos dois artigos sobreditos, outros textos mais tardios (as cartas a Newcastle e a Morus), nos falam de um único critério decisivo de distinção entre homens e animais, qual seja, a linguagem.
}

JÚNIOR, Mauro Dela Bandera Arco. La Mettrie e o cartesianismo. Griot : Revista de Filosofia, Amargosa - BA, v.18, n.2, p.348-361, dezembro, 2018. 
Se houvesse máquinas assim que tivessem os órgãos e o aspecto de um macaco ou de qualquer outro animal sem razão, não teríamos nenhum meio de reconhecer que elas não seriam, em tudo, da mesma natureza desses animais; ao passo que, se houvesse algumas que se assemelhassem a nossos corpos e imitassem as nossas ações tanto quanto moralmente é possível, teríamos sempre dois meios muito certos para reconhecer que, mesmo assim, não seriam homens verdadeiros. O primeiro é que nunca poderiam servir-se de palavras nem de outros sinais, combinando-os como fazemos para declarar aos outros nossos pensamentos. Pois se pode conceber que uma máquina seja feita de tal modo que profira palavras, e até profira algumas a propósito das ações corporais que causem alguma mudança em seus órgãos, como por exemplo, ela perguntar o que lhe queremos dizer se lhe tocamos em algum lugar, se em outro, gritar que a machucamos, e outra coisa semelhante, mas não é possível conceber que as combine de outro modo para responder ao sentido de tudo quanto dissermos em sua presença, como os homens mais embrutecidos podem fazer. E o segundo é que, embora fizessem várias coisas tão bem ou talvez melhores do que algum de nós, essas máquinas falhariam necessariamente em outras, pelas quais se descobriria que não agiam por conhecimento, mas somente pela disposição de seus órgãos. Pois, enquanto a razão é um instrumento universal, que pode servir de todas as circunstâncias, esses órgãos necessitam de alguma disposição particular para cada ação particular; daí ser moralmente impossível que haja numa máquina a diversidade suficiente de órgãos para fazê-la agir em todas as ocorrências da vida da mesma maneira que nossa razão nos faz agir. (DESCARTES. 2007, pp. 94-95).

Para Descartes, a escrita, os sinais e a fala são suportes sensíveis responsáveis por declarar o espírito, manifestá-lo, mostrá-lo, dá-lo a ver e a ouvir. Assim, a primeira das peculiaridades humanas frente ao universo animal é a capacidade de se valer da linguagem ou de signos instituídos para dar a conhecer os pensamentos e o que se passa no interior do espírito de um homem a outras pessoas que não têm um acesso direto a isso. A linguagem atesta aos outros a existência do espírito, ou ainda, garante no homem a existência de algo que vai muito além do meramente corporal. Pela linguagem, que é material, é apreendida a existência de algo espiritual e que reside única e exclusivamente no ser humano. Em uma carta endereçada ao marquês de Newcastle, de 23 de novembro de 1646, Descartes afirma:

Não há nenhuma de nossas ações exteriores que assegure aos que as examinam que nosso corpo seja algo mais do que uma máquina que se move a si mesma, mas que tem em si também uma alma que pensa, exceto as palavras ou outros sinais efetuados com relação a quaisquer objetos que se apresentam sem referência a alguma paixão. (DESCARTES, 1989, p. $574)$.

Essa disposição de exprimir com clareza o mundo do pensamento, insiste Descartes - e muitos outros repetirão -, não é determinada por nenhuma associação fixa de enunciados com estímulos externos ou estados fisiológicos. Chegamos, com isso, à segunda faculdade exclusiva do homem e que o distingue dos animais, a saber, a razão ou as ações que a testemunham. Independente da circunstância o homem é capaz de agir de acordo com a razão e não somente pela mera disposição particular

JÚNIOR, Mauro Dela Bandera Arco. La Mettrie e o cartesianismo. Griot : Revista de Filosofia, Amargosa - BA, v.18, n.2, p.348-361, dezembro, 2018. 
dos órgãos; de se conduzir de modo pertinente em qualquer que seja a situação. Como se dá então a associação entre linguagem e razão no pensamento cartesiano? Digamos a título geral que o uso da linguagem é derivado da razão. $O$ fato de falar e de responder revela uma subjetividade, uma interioridade refletindo em si a exterioridade, uma inteligência viva, em suma, conjugam a criatividade e a compreensão.

Na concepção do autor, a linguagem se explica pela presença da razão. Somente por uma diferença de natureza - a presença da razão em um, e sua ausência, em outro - chega-se a uma explicação do porquê a criança pior dotada fale, ao passo que o animal melhor dotado não o faça. Para Descartes, é patente que os animais, mesmo os mais perfeitos de sua espécie, não possuam espírito ou razão, caso contrário, falariam sem grandes dificuldades. Segue-se que os animais não falam não porque lhes faltem órgãos,

pois as pegas e os papagaios podem proferir palavras como nós; entretanto não podem falar como nós, isto é, atestando que pensam o que dizem; ao passo que os homens surdos e mudos de nascença e privados de órgãos que servem aos outros para falar, tanto ou mais que os animais, costumam eles mesmos inventar alguns sinais pelos quais se fazem entender por quem, convivendo habitualmente com eles, tem ensejo de aprender sua língua. E isto não prova somente que os animais têm menos razão que os homens, mas que não têm absolutamente nenhuma. Pois se vê que basta muito pouca razão para saber falar; e visto que se observa desigualdade tanto entre os animais de uma mesma espécie quanto entre os homens, e que uns são mais fáceis de adestrar do que os outros, não é crível que um macaco ou um papagaio, mesmo um dos mais perfeitos de sua espécie, se igualasse nisso a uma criança das mais estúpidas ou, pelo menos, a uma criança de cérebro perturbado. (DESCARTES, 2007, pp. 96-97).

É na linguagem que Descartes encontra o critério exterior não apenas do pensamento, mas também da reação criativa frente às novas situações, inventando novas línguas, novas formas de expressão necessárias a fim de compensar uma deficiência orgânica - como, por exemplo, a língua dos surdos e mudos. Em uma carta à Morus de 5 de fevereiro de 1649, Descartes se expressa nos seguintes termos:

Mas, no meu modo de pensar, o principal argumento que pode persuadirnos de que os animais são privados de razão é que, embora entre os de uma espécie alguns sejam mais perfeitos do que outros, tal como se dá entre os homens, o que é particularmente visível nos cavalos e cães, alguns dos quais têm mais disposição do que outros para reter aquilo que lhes é ensinado, e embora todos nos façam claramente compreender seus movimentos naturais de cólera, medo ou fome, e outros do mesmo tipo, quer pela voz, quer por outros movimentos do corpo, nunca porém foi observado que algum animal tenha chegado a um grau de perfeição que o torne capaz de fazer uso de uma verdadeira linguagem; isto é, seja capaz de indicar-nos pela voz, ou por outros sinais, algo que possa ser unicamente relacionado com o pensamento e não apenas com um movimento natural; pois a fala é o único sinal e a única marca certa da presença do pensamento, oculto e envolvido pelo corpo; ora, todos os homens, mesmo os mais estúpidos e os mais insensatos, ainda aqueles que são privados dos órgãos da língua e da fala, empregam sinais, enquanto os animais jamais fazem coisa semelhante; o que pode ser considerado a

JÚNIOR, Mauro Dela Bandera Arco. La Mettrie e o cartesianismo. Griot : Revista de Filosofia, Amargosa - BA, v.18, n.2, p.348-361, dezembro, 2018. 
verdadeira distinção entre o homem e o animal. (DESCARTES, 1973, p. $886)^{8}$

Conclui-se que não é simplesmente o uso de palavras que distingue o homem do animal ou do autômato, pois se "pode conceber que uma máquina seja feita de tal modo que profira palavras" e, além disso, animais como "as pegas e os papagaios podem proferir palavras como nós" - lembremos o caso visto por Leibniz de um cachorro capaz de proferir algumas palavras em francês e alemão ${ }^{9}$. $O$ que não se pode esperar dos animais ou dos autômatos é que combinem as palavras "de outro modo para responder ao sentido de tudo quanto dissermos em sua presença, como os homens mais embrutecidos podem fazer"; é inconcebível, para Descartes, que eles possam "falar como nós", ou que façam "uso de uma verdadeira linguagem". Não se espera que eles sejam capazes "de indicar-nos pela voz, ou por outros sinais, algo que possa ser unicamente relacionado com o pensamento e não apenas com um movimento da mera natureza" ou das paixões. Colocando em outros termos, enquanto o autômato pode vir a pronunciar somente aquilo que lhe foi "programado" fazer e o animal pode proferir somente aquilo que o adestramento e o treinamento lhe possibilitaram, o homem, por sua vez, é capaz de utilizar as palavras de modo a compô-las e arranjá-las de diversas maneiras para atender convenientemente a todas as exigências da vida. Ele possui a razão e a capacidade de formar "uma verdadeira linguagem", com novas proposições que exprimam novos pensamentos e sejam apropriados a novas situações; pode se adequar e dar respostas satisfatórias e diferentes, não importando as circunstâncias.

Vemos que as duas faculdades humanas estão essencialmente implicadas. Há no uso ordinário da palavra uma maneira de agir adaptada a todo tipo de ocasião, isto é, um aspecto criativo da linguagem calcado na razão. Como diria Jean-Claude Pariente,

o que faz precisamente a linguagem humana é a atitude de compor "diversamente" esses signos para se adaptar e responder às significações: é precisamente na atitude de organizar signos em frases ou proposições que Descartes situa o descompasso do homem em relação ao reino mecânico e animal. Essa atitude ligada ao uso humano dos signos traduz um poder de diversificação que ultrapassa tudo o que a disposição dos órgãos poderia

\footnotetext{
${ }^{8}$ Lembrando que, no entender de Descartes, falar é justamente a capacidade do homem de se valer da linguagem para dar a conhecer seu pensamento e não para exprimir as paixões e os movimentos naturais como cólera, medo, fome e outros do mesmo tipo. Descartes insiste que não se deve de forma alguma "confundir as palavras com os movimentos naturais, que expressam as paixões e podem ser imitados tanto pelas máquinas quanto pelos animais, nem pensar, como alguns autores antigos, que os animais falam, embora não entendamos sua linguagem" (DESCARTES, 2007, p. 97).

9 "Sem um fiador como Leibniz, testemunha ocular, não teríamos a ousadia de relatar que perto de Zeits em Misnie existe um cão que fala. É um cão de camponês, de figura das mais comuns e de tamanho medíocre. Uma criança pequena ouviu-o pronunciar alguns sons que acreditou se assemelhar a palavras alemãs e, nisso, colocou na cabeça ensinar-lhe a falar. O mestre, que não tinha nada melhor para fazer, não poupou tempo, nem suas dificuldades e o discípulo, felizmente, tinha disposições difíceis de serem encontradas em outro. Por fim, depois de alguns anos, o cão soube pronunciar cerca de trinta palavras. Contam nesse número termos como Chá, Café, Chocolate, Assembleia, palavras francesas que passaram ao alemão tais como são. Deve-se notar que o cão tinha três anos quando foi colocado na escola. Ele fala apenas por eco, isto é, depois de ter seu mestre pronunciado uma palavra, e parece que ele repete apenas por força e apesar de si mesmo; muito embora não seja maltratado. Mais uma vez, Leibniz o viu e o ouviu" (Histoire de l'Académie Royale des Sciences, 1715, Paris, Imprimerie Royale, 1718, pp. 3-4; apud BUFFON, 2008, p. 464, notas de Stéphane Schmitt).
}

JÚNIOR, Mauro Dela Bandera Arco. La Mettrie e o cartesianismo. Griot : Revista de Filosofia, Amargosa - BA, v.18, n.2, p.348-361, dezembro, 2018. 
explicar e recorta a atitude de agir de maneira adaptada "em todo tipo de ocasião" que é uma outra marca da razão. Portanto, Descartes não associa simplesmente razão e linguagem, no sentido de uso de signos. Ele reconhece na linguagem humana uma característica singular, sua organização em frases, e é essa característica que ele associa à razão, constatando que elas estão presentes até mesmo nos "insensatos ou nas crianças estúpidas" e ambas ausentes, até mesmo num animal "que seria o mais perfeito de sua espécie". (PARIENTE, 1985, p. 55).

Vemos de forma nítida a concepção dualista de Descartes. O homem possui um corpo mecânico como todos os outros corpos e, ao mesmo tempo, é o único ser que possui um espírito, uma interioridade. Estas duas substâncias (coisa extensa e coisa pensante) constatadas no homem impedem a continuidade da cadeia dos seres entre o universo humano e o universo animal, dado que os animais são desprovidos de uma delas. Eles são desprovidos da faculdade superior, da alma ou espírito, que não se deixa apreender pelas leis da mecânica. Esta concepção dualista assegura uma fronteira intransponível entre a esfera humana e a animal. Em outras palavras, a teoria dos animais-máquinas e dos autômatos é uma consequência do dualismo defendido por Descartes.

A aparição do Homem máquina parece não deixar dúvidas quanto aos reais propósitos do autor. Todos conheciam os animais-máquinas, sobretudo o que eles se tornaram nas mãos dos cartesianos. Independentemente do que pôde ter sido o escopo desta teoria para o próprio Descartes, os animais eram, para os partidários de sua filosofia, meros autômatos sem pensamento nem sentimento. Quem não conhecia a anedota dos senhores de Port-Royal que davam pontapés nos cachorros explicando seus uivos como um efeito puramente mecânico? Nicolas Fontaine (1625-1709) assegura que os homens de Port-Royal conheciam e até mesmo discutiam o tema dos animais presente na obra de Descartes. Eles se agitavam a propósito do cartesianismo e, desta filosofia, eram as teses sobre os animais e os autômatos que retinham de uma maneira toda particular sua atenção. Citemos:

\begin{abstract}
Quanto também, escreve ele, elevaram-se pequenas agitações neste deserto tocando as ciências humanas da filosofia, e as novas opiniões de Descartes? Como Arnauld, em suas horas de descanso, com isso se entretinha na companhia de seus amigos mais íntimos, o que insensivelmente se espalhou por toda parte, e esta solidão, nas horas de entretenimento, não ressoava senão destes discursos. Quase não havia mais solitário que não falasse de autômato. Não se fazia mais um caso ao bater em um cachorro. Dava-se nele indiferentemente golpes de bastão e ria-se daqueles que se apiedavam dessas bestas como se elas tivessem sentido dor. (apud PARIENTE, 1985, p. 53).
\end{abstract}

Neste contexto, o termo "homem máquina" parece significar para qualquer intérprete que o homem seria apenas um autômato do mesmo tipo que o animal, isto é, um ser puramente mecânico (THOMSON, 1987, p. 19). Em resumo, o homem não seria capaz de pensar, nem ao menos de sentir. O próprio La Mettrie sugere esta

JÚNIOR, Mauro Dela Bandera Arco. La Mettrie e o cartesianismo. Griot : Revista de Filosofia, Amargosa - BA, v.18, n.2, p.348-361, dezembro, 2018. 
interpretação ao saudar a filosofia de Descartes como pioneira, um modelo para a construção da teoria do homem-máquina, uma vez que preparara filosoficamente o terreno. "Ele conheceu a natureza animal" e "foi o primeiro a demonstrar perfeitamente que os animais eram puras máquinas" (LA METTRIE, 1981, p. 106). Por analogia, o argumento é estendido para também abarcar o homem. Nestes termos, Descartes só teria reconhecido a existência das duas substâncias distintas no homem (o dualismo alma e corpo) para evitar maiores problemas com a censura da igreja. Nas palavras de La Mettrie: embora Descartes "fale sobre a distinção das duas substâncias, é visível que isso não passa de um truque de destreza, uma astúcia de estilo, para fazer com que os teólogos engulam um veneno escondido na sobra de uma analogia que salta aos olhos de todos e que apenas eles não veem" (idem, p. 206). Assim, Descartes seria um materialista sem ousar dizê-lo. Apesar de todos os equívocos, ele teria oferecido a chave para a compreensão da natureza humana.

O título do livro de La Mettrie - "um feliz golpe midiático" (THOMSON, 1987, p. 19) - ludibriou os leitores que, por sua vez, fizeram do autor o partidário de um "materialismo mecanicista" (idem, p. 20) que estenderia as considerações cartesianas sobre os animais para também abarcar a totalidade dos fenômenos humanos. Contudo, uma leitura atenta basta para afastar a ideia do homem como um puro e simples autômato. Aliás, a doutrina lamettriana (de certa maneira herdeira do empirismo da época) se afasta enormemente da doutrina cartesiana ao defender que os animais não somente são capazes de sentir, mas também de pensar, o que acaba por recusar o dualismo de Descartes. La Mettrie "recusa explicitamente a teoria cartesiana dos animais-máquinas, como uma concepção absurda e contrária à experiência" (MOUTAUX, 1987, p. 6). Ademais, sua acepção de matéria é também bastante distinta da definida por Descartes. A matéria, considerada como substância dos corpos e como objeto das percepções, sempre possui "uma força motriz e, por conseguinte, a faculdade de sentir" - o que acaba por negar muito claramente a concepção cartesiana da matéria como simples extensão (THOMSON, 1987, p. 21). La Mettrie defende uma concepção dinâmica da matéria como substância ativa e sensível.

Não sendo sua intenção transportar ao homem, ou melhor, ao corpo humano, a caracterização mecânico-maquinal do corpo animal, seu trabalho não se limita a desenvolver o aspecto material do dualismo cartesiano e, por conseguinte, a deixar de lado os questionamentos sobre a alma. Mais do que isso, ele pretende incluir a alma nessa mecânica e, consequentemente, explicar o aparecimento do pensamento por meio da matéria organizada. Duas afirmações ratificam o propósito do autor: "o corpo humano é uma máquina que monta ela mesma suas peças (ressorts)" (LA METTRIE, 1981, p. 152), e "a alma é apenas um princípio de movimento ou uma parte material sensível do cérebro" (idem, p. 198). Nas palavras do autor, "todas as faculdades da alma dependem da própria organização do cérebro e de todo o corpo, não sendo senão essa própria organização" (idem, p. 189). Portanto, a alma humana é puramente material. Assim, todas as faculdades, compreendida também a inteligência, derivam da matéria em movimento. O esforço de La Mettrie reside na tentativa de explicar as faculdades intelectuais como resultado do funcionamento do organismo, e não em virtude de uma alma imaterial. Todas as funções intelectuais do

JÚNIOR, Mauro Dela Bandera Arco. La Mettrie e o cartesianismo. Griot : Revista de Filosofia, Amargosa - BA, v.18, n.2, p.348-361, dezembro, 2018. 
homem, assim como do animal, resultam de uma organização particular da matéria, no cérebro.

Com isso, a diferença entre o homem e o animal restringe-se apenas ao grau, sendo o ser humano o melhor organizado ou, podemos dizer, o mais perfeito. Neste sentido, a organização é o primeiro mérito do ser humano (LA METTRIE, 1981, p. 169). Do mesmo modo que os animais, o homem é também um ser puramente material. $O$ que o distingue dos animais é uma inteligência superior vinda da maior complexidade de seu cérebro. A fisiologia comparada prova a conformidade essencial da estrutura dos animais e dos seres humanos. Esta conformidade se estende também ao cérebro, o órgão do pensamento. Em geral, "a forma e a composição do cérebro dos quadrúpedes é aproximadamente a mesma do homem. Mesma figura, mesma disposição; com a diferença essencial de que o homem é de todos animais o que tem mais cérebro" (idem, p. 157). Depois do homem, continua o autor, vêm o macaco, o castor, o elefante, o cachorro, etc. A oscilação dos corpos organizados explica todas as faculdades e as diferenças dos seres. Se tudo deriva da organização da matéria, não há propriamente um critério válido para distinguir radicalmente homens e animais; não há uma distinção entre um e outro universo; mas apenas continuidade.

$O$ papel da linguagem é fundamental para distinguir o homem cultivado dos demais seres, pois permite ao homem desenvolver as potencialidades do cérebro. Donde a importância da educação, sendo ela o segundo (idem, p. 170) mérito do ser humano. Sem educação e instrução, mesmo o cérebro melhor construído não seria grande coisa. Por isso é possível falar da hipótese de uma educação dos grandes macacos antropoides. O médico-filósofo postula a possibilidade de realizar a continuidade homem-animal a ponto de inclusive fazer o animal falar.

Tanto na História da alma (1745) quanto no Homem máquina, La Mettrie considerou os macacos como animais passíveis de serem educados e humanizados, algo próximo ao símio kafkiano, Pedro Vermelho, que se eleva paulatinamente à humanidade por meio da educação, deixando para trás sua condição de símio (KAFKA, 2003). Tendo em vista a analogia essencial de seu cérebro e o do homem, ele aprenderia a falar (pelo método de Amman) e se tornaria um homem perfeito. Dotado de uma organização semelhante, ele é passível de ser educado e instruído, eis o projeto sugerido por La Mettrie.

Entre os animais, uns aprendem a falar e a cantar; retêm as árias e captam todos os tons de maneira tão exata como se fossem um músico. Outros que, no entanto, mostram mais espírito, como o macaco, não o conseguem fazer. E por que, se isso não for causado por um vício dos órgãos da fala? | Mas esse vício é de tal modo de conformação que não se pode dar-lhe nenhum remédio? Em uma palavra, seria absolutamente impossível ensinar uma língua a esse animal? Não o creio. (LA METTRIE, 1981, pp. 159-160).

La Mettrie escolhe "o grande macaco" preferencialmente a todos os outros animais, pois ele se assemelha a tal ponto ao ser humano que "os naturalistas deramlhe o nome de homem selvagem ou homem dos bosques/da floresta" (idem, p. 160) ${ }^{10}$. 0 10 "Tomá-lo-ia em condições semelhantes às dos alunos de Amman, isto é, gostaria que ele não fosse nem muito
jovem nem muito velho, pois os que chegam à Europa são em geral muito idosos. Escolherei um que tivesse a

JÚNIOR, Mauro Dela Bandera Arco. La Mettrie e o cartesianismo. Griot : Revista de Filosofia, Amargosa - BA, v.18, n.2, p.348-361, dezembro, 2018. 
autor não hesita em defender que se pode remediar o mutismo dos macacos por um método educacional, do mesmo modo que é viável ensinar os surdos a modular a voz e pronunciar palavras, tal como demonstrou Johann Conrad Amman (1669-1730) em seu método ${ }^{11}$.

Pelo livro de Amman e por todos aqueles que traduziram seu método, sabeis de todos os prodígios que ele conseguiu operar nos surdos de nascença, em cujos olhos, como ele mesmo diz, soube encontrar orelhas e que em pouco tempo ele lhes ensinou a escutar, falar, ler e escrever. Aceito que os olhos de um surdo vejam mais claro e sejam mais inteligentes do que se ele não o fosse, em virtude de que a perda de um membro ou de um sentido pode aumentar a força ou a penetração de um outro. (LA METTRIE, 1981, pp. 160-161).

Se Amman realizou prodígios em seus alunos, o que dizer então de uma educação direcionada aos grandes macacos antropoides? Há ainda a vantagem de que "o macaco vê e ouve, compreende o que ouve e o que vê". Ele também "concebe com tanta perfeição os signos que lhe fazemos, que em qualquer outro jogo ou exercício", La Mettrie não duvida, "ele ultrapassaria os discípulos de Amman" (idem, p. 161).

Por que, então, a educação dos macacos seria impossível? Por que ele não poderia à custa de cuidados e a exemplo dos surdos imitar os movimentos necessários à pronunciação? Não ouso sustentar se os órgãos da fala do macaco não podem - o que fazemos - articular; no entanto, essa impossibilidade absoluta me surpreenderia, em virtude da grande analogia do macaco e do homem e tendo em conta que não existe nenhum animal conhecido até o presente que cujo interior e o exterior se lhe assemelhe de maneira tão surpreendente. (idem, p. 161).

Dada a semelhança que se pode constatar entre os macacos antropoides e os homens - semelhança tanto no registro interno quanto externo -, La Mettrie desafia qualquer um a lhe citar pelo menos uma "experiência conclusiva" que inviabilize seu projeto de educação. Além disso,

a similitude da estrutura e das operações do macaco é tanta que não duvido que se se treinasse perfeitamente este animal, se conseguiria ensinálo a pronunciar e, por conseguinte, a saber uma língua. Então ele não seria mais um homem selvagem tampouco um homem falho (manqué): mas um homem perfeito, um pequeno homem de cidade, com tanta coisa ou músculos quanto nós mesmos para pensar e aproveitar sua educação. (idem, pp. 162-163).

Aos olhos do autor, por meio da educação é possível humanizar os macacos antropoides. Aliás, a educação é o elemento chave para se compreender os

fisionomia mais espirituosa e que melhor correspondesse em mil pequenas operações ao que ela me prometia. Por fim, por não me achar digno de ser seu governante, colocá-lo-ia na escola do excelente mestre que acabo de citar ou, caso houvesse - de outro tão hábil quanto ele" (idem, p. 160).

11 O método, para o discípulo surdo, consistia "em tocar a garganta do mestre que fala, em seguida em examinar sua própria garganta tendo em vista perceber os tremores dos órgãos da fala, depois em repetir os movimentos da fonação diante de um espelho até atingir a perfeita execução" (ASSOUN, 1981, pp. 244-245, note 57).

JÚNIOR, Mauro Dela Bandera Arco. La Mettrie e o cartesianismo. Griot : Revista de Filosofia, Amargosa - BA, v.18, n.2, p.348-361, dezembro, 2018. 
desenvolvimentos e os progressos constatados nos seres humanos. Sem ela o homem seria um animal como qualquer outro ou até mesmo estaria, em um primeiro momento, abaixo dele (idem, p. 174), pois se contarmos unicamente o instinto, o homem o tem menos desenvolvido (idem, p. 173). De acordo com La Mettrie, somente o homem, desprovido de instinto e de educação, desconhece os alimentos que lhe são próprios e, portanto, somente ele morreria de fome em meio a um rio de leite; igualmente, somente o ser humano cairia na beira de um precipício. $O$ homem, sem a invenção e a aprendizagem da linguagem, sem o "conhecimento simbólico", não é nada além de um diamante bruto que precisa ser lapidado.

O que era um homem antes da invenção das palavras e do conhecimento
das línguas? Um animal de sua espécie com muito menos instinto natural
do que os outros, dos quais ele então não se julgava o rei, sendo distinguido
do macaco e dos outros animais apenas como o macaco o faz ele mesmo, ou
seja, por uma fisionomia que anuncia um maior discernimento. Reduzido
apenas ao conhecimento instintivo dos leibnizianos, ele limitava-se a ver
figuras e cores sem nada distinguir entre elas; velho e jovem, mas sempre
criança, ele gaguejava suas sensações e necessidades da mesma forma que
um cão esfomeado ou entediado por não fazer nada pede para comer ou
passear. (idem, p. 163).

Se os homens conseguiram compreender o uso dos signos e o conhecimento simbólico de modo a se tornarem o que são, os macacos antropoides também poderão fazê-lo, já que eles também são capazes de entender o sistema dos signos. Os grandes macacos antropoides poderão tornar-se verdadeiros homens, demonstrando com isso uma continuidade na grande cadeia dos seres e uma não diferenciação absoluta entre animalidade e humanidade. Poderão vir a ser algo como Pedro Vermelho que, diante de uma plateia de acadêmicos, pronuncia seu discurso.

Portanto, apesar de se afirmar - e o próprio La Mettrie sustentar - que existiria uma continuidade natural entre o animal-máquina cartesiano e o homemmáquina lamettriano, e que de uma hipótese à outra haveria apenas um passo, a diferença entre os dois autores é gigante. "Em Descartes, a tese do animal-máquina é a consequência do dualismo da alma e do corpo, do qual constitui ao mesmo tempo a confirmação experimental; ao passo que em La Mettrie, a tese do homem-máquina confirma o monismo radical que ele serve para expor" (ASSOUN, 1981, p. 55). Ao materializar a alma, como bem notou Catherine Larrère, La Mettrie "não leva até as últimas a posição de Descartes", ao contrário, sua hipótese questiona a própria posição e o próprio núcleo da filosofia cartesiana, "pois ao afirmar a materialidade da alma, ele anula a distinção do sujeito e do objeto e, assim, a distância que ela estabelecia entre o homem e o animal" (LARRÈRE, 2010, p. 95). Diferentemente do que se passa na teoria de Descartes, o Homem-máquina estabelece uma tese continuísta entre homens e animais. Dessa maneira, o pensamento e a linguagem não podem ser elevados enquanto critérios capazes de distinguir um universo do outro, tal como manifesto na filosofia cartesiana. 


\section{Referências}

ASSOUN, Paul-Laurent. "Lire La Mettrie". In: La Mettrie, Julien Offroy de. L'homme-Machine. Paris : Éditions Denoël/Gonthier, 1981.

BOUGEANT. Amusement philosophique sur le langage des bêtes. Genève : Librairie Droz; Lille : Librairie Giard, 1954.

BOULLIER. Essai philosophique sur l'âme des bêtes. Paris: Fayard, 1985.

BUFFON. Histoire naturelle. Tome II. Paris : H. Champion, 2008.

Histoire naturelle. Tome IV. Paris : H. Champion, 2010.

CONDILLAC. Traité des animaux. Paris : J. Vrin, 2004.

DESCARTES, René. Discurso do método. Tradução de Maria Ermantina de Almeida Prado Galvão. São Paulo: Martins Fontes, 2007.

Méditation métaphysique. «Réponse de l'auteur aux sixièmes objections

faites par divers Théologiens, Philosophes et Géomètres ». Euvres. Tome IX. Paris : J. V rin, 1996.

Cuvres de Descartes. Correspondance. Tome IV. Juillet 1643 - Avril 1647. Paris: J. Vrin, 1989.

. Euvres philosophiques. Tome III (1643-1650). Tradução revisada e corrigida por Ferdinand Alquié da edição parisiense de 1724-1725. Paris: Éditions Garnier, 1973.

DIDEROT. La suite d'un entretien entre M. d'Alembert et M. Diderot / Le rêve de d'Alembert / Suite de l'entretien précédent. Euvres philosophiques. Paris: Éditions Gallimard, 2010.

; D'ALEMBERT, Jean le Rond. Encyclopédie ou dictionnaire raisonné des sciences, des arts et des métiers. Edição online : http://encyclopedie.uchicago.edu/. Consultado em 17/04/2017.

EHRARD, Jean. L’idée de nature en France dans la première moitié du XVIIIe siècle. Paris : Albin Michel, 1994.

FONTENAY, Élisabeth de. Le silence des bêtes: la philosophie à l'épreuve de la animalité. Paris : Fayard, 1998, pp. 465-478.

GONTIER, Thierry. "Descartes et les animaux-machines : une réhabilitation?". In : De l'animal-machine à l'âme des machines: Querelles biomécaniques de l'âme (XVIIe-XXIe siècles).

. « Les animaux-machines chez Descartes : modèle ou réalité ? ». In : Corpus.

«L'âme des bêtes ». Paris: Fayard, 1991, n. 16/17.

HASTINGS, Hester. Man and Beast in French Thought of the 18th Century. Baltimore: The Johns Hopkins Studies in Romance Literatures and Languages, vol. XXVII, 1936.

KAFKA, Franz. "Um relatório para uma academia". In: Um médico rural. Tradução de Modesto Carone. São Paulo: Companhia das Letras, 2003.

LA METTRIE, Julien Offroy de. L'homme-Machine. Paris: Éditions Denoël/Gonthier, 1981, p. 152.

LARRÈRE, Catherine. «Des animaux-machines aux machines animales ». In : Qui sont les animaux? Sous la direction de Jean Birnbaum. Paris : Éditions Gallimard, 2010 .

JÚNIOR, Mauro Dela Bandera Arco. La Mettrie e o cartesianismo. Griot : Revista de Filosofia, Amargosa - BA, v.18, n.2, p.348-361, dezembro, 2018. 
LE ROY, Charles-Georges. Sur l'intelligence des animaux. Paris : Édition Sillage, 2017, p. 172.

MCGUIRE, John P. «Défendre le matérialisme: Rousseau contre Buffon sur l'histoire naturelle de l'âme ». In : Philosophie de Rousseau. Sous la direction de Blaise Bachofen, Bruno Bernardi, André Charrak et Florent Guénard. Paris : Classiques Garnier, 2014.

MOUTAUX, Jacques. «Matérialisme et Lumières ». Corpus $\mathrm{n}^{\circ}$ 5/6, La Mettrie, France,

mis en oeuvre par Francine Markovits, pp. 3-13.

PARIENTE, Jean-Claude. L'analyse du langage à Port-Royal: six études logicogrammaticales. Paris: Éditions de Minuit, 1985.

SOUZA, Maria das Graças de. Natureza e ilustração: sobre o materialismo de Diderot. São Paulo: Editora Unesp, 2002.

THOMSON, Ann. « La Mettrie ou la machine infernale ». Corpus n 5/6, La Mettrie, France, 1987, mis en oeuvre par Francine Markovits, pp. 15-26.

VARTANiAN, Aram. « La Mettrie et la science ». Corpus $\mathrm{n}^{\circ}$ 5/6, La Mettrie, France, 1987, mis en oeuvre par Francine Markovits, pp. 53-61.

Autor(a) para correspondência: Mauro Dela Bandera Arco Júnior, Universidade de São Paulo, Faculdade de Filosofia, Letras e Ciências Humanas, R. do Lago, 717 - Butantã, CEP 03178-200, São Paulo-SP, Brasil.maurodelabandera@yahoo.com.br 